\title{
Trends in the prescription of benzodiazepines for the elderly in Korea
}

\author{
Soo-Hee Hwang ${ }^{1}$, Seungjin Han ${ }^{1}$, Hyojung Choi ${ }^{1}$, Choonseon Park', Sun Min Kim ${ }^{1}$ and Tae Hyun Kim² ${ }^{2 *}$
}

\begin{abstract}
Background: This study examined trends in the prescription of benzodiazepines for the elderly (age over 65 years) in Korea, a country with a higher level of spending on pharmaceuticals compared to that in other Organization for Economic Cooperation and Development (OECD) countries, and identified factors related to the inappropriate use of such drugs.

Methods: We used the National Health Insurance Claims Data (NHICD) for the period 2009-2013, including all reimbursed drug-prescribing information. Following the OECD's prescribing quality indicators (PQIs), we looked at the prevalence, quantities, durations, and inappropriate (long-term or high-quantity) use of benzodiazepines, some of the most widely prescribed, but potentially inappropriate, drugs for the elderly. We also performed multivariate logistic regression analyses to identify factors related to the inappropriate use of these drugs.
\end{abstract}

Results: The annual prevalence of benzodiazepine prescribing for elderly subjects decreased slightly over time but remained high (37.9\% in 2009 and 35.1\% in 2013). There were also small decreases in the inappropriate long-term use of benzodiazepines over the five years, with a 0.6 decrease in the Defined Daily Dose and a 4.1 per 1,000 decreases in elderly user-days. The proportion of subjects using long-acting benzodiazepines also fell from 263.6 to 220.4 per 1,000 elderly patients. The regression analyses found that the inappropriate long-term use of benzodiazepines in the elderly was significantly related to the patients visiting several institutions and physicians prescribing more than 30 days' worth of medication.

Conclusions: The prevalence of prescribing potentially inappropriate drugs, such as benzodiazepines, remains high in Korea. Policy efforts, such as a periodic assessment of prescribing, restricting prescribing days, and more practical guidelines, are needed to improve the quality of prescribing.

Keywords: Benzodiazepines, Elderly, Inappropriate drugs, Prescribing quality indicators

\section{Background}

As some of the most widely prescribed drugs, benzodiazepines and related drugs are commonly used among the elderly for the treatment of anxiety, insomnia, muscle spasm, and epilepsy, despite the well-known risks for older people [1-4]. According to the recently updated Beers criteria, it is strongly recommended that benzodiazepines be avoided for the treatment of insomnia, agitation, or delirium in older people, because such patients have an increased sensitivity to the drugs and slower metabolism [5]. However, older people are still the largest consumers of

\footnotetext{
* Correspondence: thkim@yuhs.ac

${ }^{2}$ Department of Hospital Administration, Graduate School of Public Health, Institute of Health Services Research, Yonsei University, 50-1 Yonsei-ro, Seodaemun-gu, 03711 Seoul, Republic of Korea

Full list of author information is available at the end of the article
}

benzodiazepines $[1,6,7]$, and this may be associated with poor health outcomes, such as falls, fractures, cognitive impairment, and dependence $[4,8]$.

Recently, the Health Care Quality Indicator (HCQI) project of the Organization for Economic Cooperation and Development (OECD) introduced prescribing quality indicators (PQIs) for primary health care. Among these, some medication safety indicators are used as prescribing indicators to measure the potentially inappropriate use of benzodiazepines in the elderly, because this therapeutic area has stood out as one of the most concerning issues in many countries [9].

Korea has higher levels of spending on pharmaceuticals compared to other OECD countries, with pharmaceuticals accounting for approximately $20.6 \%$ of the total 
expenditure on health insurance in 2013. The country has also been rapidly moving toward an aged society, with the elderly population rising sharply [10]. A systematic intervention and monitoring system for managing the quality of prescriptions in older people at the government level is needed in Korea. [7] A recent study showed that benzodiazepines were one of the most common medications prescribed inappropriately to aged people in Korea, based on the American Geriatric Society updated Beers criteria list. [11] The Korean government started enforcing a policy regulating the number of prescribing days for sedatives and hypnotics $(<30$ days per prescription) in 2010 [7]. However, so far, there have been no federal policies/strategies to manage the full spectrum of benzodiazepines.

The aims of this study were to investigate the prescribing patterns and prevalence of the inappropriate use of benzodiazepines for older people in Korea by applying the newly developed PQIs of the OECD HCQI project to identify the scale of potentially problematic benzodiazepine prescribing. We also examined the potential risk factors related to the inappropriate use of benzodiazepines to discuss and suggest changes to the existing policy.

\section{Methods}

\section{Data source}

The National Health Insurance Claims Data (NHICD) submitted to the Health Insurance Review \& Assessment Service (HIRA) for the period from 2009 to 2013 was used for this study. The study period included 2010, when the new regulation went into effect limiting the prescription days of some classes of sedatives and hypnotics. The HIRA is in charge of claims review and quality improvement under Korea's single-payer health insurance system, and the HIRA's database broadly represents the Korean population in terms of sex, age, and geography [12]. The database contains de-identified information on the patients' age, gender, type of insurance (National Health Insurance or Medical Aid, a public assistance program for low-income households that assists with self-help by providing medical services), diagnoses, procedures and operations, type of medical services, institution(s) visited, visit dates, prescriber's identification number and prescribed and dispensed medications [13]. The database also contains detailed prescription and dispensing information, including Korean drug codes, brand names, quantities, and durations of prescribing and dispensing. For a more accurate analysis, we used the dispensing data.

\section{Study subjects}

The study population consisted of outpatients aged over 65 years as of July 1st each year who were prescribed benzodiazepines and related drugs at least once during the study period. The World Health Organization (WHO) Anatomical-Therapeutic-Chemical (ATC) coding and categorization system for drug data coding was used to classify medications. Benzodiazepines and related drugs include ATC codes N05BA (anxiolytics containing benzodiazepine derivatives), N05CD (hypnotics containing benzodiazepine derivatives), N03AE01 (clonazepam, antiepileptics), and N05CF (hypnotics containing benzodiazepine-related drugs).

Patients who were prescribed benzodiazepines that were not assigned a Defined Daily Dose (DDD) were excluded from this study (clotiazepam, etizolam, pinazepam, etc., approximately $10.7 \%$ of the patients). We also excluded subjects prescribed benzodiazepines for conscious sedation endoscopy (approximately 3.7\%).

\section{Measures of inappropriate prescribing}

The inappropriate use of benzodiazepines for the elderly was measured using the newly proposed PQIs in the primary care of the OECD's HCQI project. The PQIs for the inappropriate prescribing of benzodiazepines included the long-term use of benzodiazepines (patients who were prescribed benzodiazepines over 365 DDDs/ year, 567.5 DDDs/year, 365 days/year, or 547.5 days/year) or who received at one or more prescription of longacting benzodiazepines [9]. Of these five indicators, we only considered the long-term use of benzodiazepines as the use over 365 DDDs/year, 365 days/year, and the use of long-acting benzodiazepines because the thresholds of 567.5 DDDs/year and 547.5 days/year were too high and had a very low prevalence.

\section{Statistical analysis}

We focused on the usage patterns and safety of benzodiazepine prescriptions for older people. The prevalence of benzodiazepine prescriptions in the elderly population and the mean prescription quantities (DDD) and durations (user-days) were calculated with respect to the patient age, sex, and type of insurance. The overall volume of benzodiazepine prescription was presented as the DDDs and user-days and per 1000 elderly population per day. The inappropriate use of benzodiazepines was presented as the rate per 1000 elderly population each year. Finally, we carried out multivariate logistic regression analyses on the benzodiazepine users in 2013 to investigate the factor potentially related to inappropriate use. The analyses were adjusted for each demographic characteristic, the number of institutions utilized, and the main disease cited as the indication for benzodiazepine prescription. Adjusted odds ratios (ORs) with 95\% confidence intervals (CIs) were calculated.

Data extraction and statistical analyses were conducted with Statistical Analysis Software (SAS) Enterprise Guide Version 4.3 (SAS Institute, Inc., Cary, NC). Denominator 
information on the Korean population was downloaded from Statistics Korea (http://kosis.kr/statisticsList/statisticsList_01List.jsp?vwcd=MT_ZTITLE\&parentId=A\#SubCont).

\section{Results}

Prevalence and patterns of benzodiazepine prescriptions

The study population was about 5.3 million elderly in 2009 and 6.3 million elderly in 2013, and the number of patients prescribed benzodiazepines at least once was about 2.0 and 2.2 million elderly, respectively. From 2009 to 2013, the prevalence of patients prescribed benzodiazepines slightly decreased from $37.9 \%$ to $35.1 \%$ $(-2.8 \%)$, with the smallest decline in the $80-84$ age group $(-0.8 \%)$. However, in the Medical Aid group, the prevalence of benzodiazepine prescriptions rose from $12.7 \%$ to $13.5 \%(+0.8 \%)$. Females were about $10 \%$ more likely to be prescribed benzodiazepines compared to males (Table 1).

The overall volume of benzodiazepine prescriptions among the elderly in 2009 was 66.1 DDDs/1000 population/day and 136.6 days/1000 population/day, but it steadily declined over the five-year period by 3.7 DDDs and 9.7 days in terms of the quantity and duration, respectively. However, the patterns of benzodiazepine prescriptions in the older (80-84- and over 85-year-olds) and Medical Aid groups remained nearly unchanged or increased (Fig. 1).

\section{Inappropriate long-term use of benzodiazepines}

The proportion of patients prescribed more than 365 $\mathrm{DDD} /$ year of benzodiazepines steadily decreased from $12.2 / 1000$ elderly in 2009 to $11.4 / 1000$ elderly in 2011, but the rate remained unchanged during the next two years. For the Medical Aid group, however, the proportion of long-term use of benzodiazepines increased by $0.4 / 1000$ elderly over the five years.
In terms of the duration, the proportion of patients prescribed more than 365 days/year also decreased from 42.6/1000 elderly in 2009 to $38.5 / 1000$ elderly in 2013. The extent of the reduction of the inappropriate use over the study period decreased with age, and the inappropriate use increased in the oldest age group (85+). In the Medical Aid group, the value also increased by $0.7 / 1000$ elderly over the five years (Table 2).

When inappropriate use was assessed based on the prescribing of long-acting benzodiazepines, another measure of inappropriateness, there were 264 individuals per 1000 elderly people who were prescribed long-acting benzodiazepines in 2009, showing a decreasing pattern over the five years $(-43.2 / 1000$ elderly). Similar to the other measures, there was little improvement in the Medical Aid group (Table 3).

Factors potentially related to inappropriate long-term use Males and the Medical Aid group were significantly more likely to have inappropriate benzodiazepine use, but the effect of age produced contradictory results in the DDDs and user-days model. In addition, we found that inappropriate benzodiazepine use was strongly associated with the utilization of multiple health care providers throughout the year, the presence of at least one benzodiazepine prescription for 30 days or more, and the receipt of at least one benzodiazepine prescription for a psychiatric disorder (Table 4).

\section{Discussion}

Prevalence and patterns of benzodiazepine prescriptions

The results of the study indicate that there was a high prevalence and a slightly decreasing trend in the prescribing of benzodiazepines and related drugs in the elderly during the study period. The prevalence of

Table 1 Prevalence of benzodiazepine prescriptions from 2009 to 2013

\begin{tabular}{|c|c|c|c|c|c|c|c|}
\hline & & 2009 & 2010 & 2011 & 2012 & 2013 & $\begin{array}{l}\text { Difference } \\
2009-2013\end{array}$ \\
\hline & & \multicolumn{6}{|l|}{$(\%)$} \\
\hline Total & & 37.9 & 37.2 & 36.5 & 36.1 & 35.1 & -2.8 \\
\hline \multirow[t]{5}{*}{ Age group (year) } & $65-69$ & 36.4 & 35.9 & 34.5 & 34.1 & 31.6 & -4.8 \\
\hline & $70-74$ & 39.8 & 39.1 & 38.2 & 37 & 37.2 & -2.6 \\
\hline & $75-79$ & 40.6 & 39.6 & 39.7 & 39.7 & 38.7 & -1.9 \\
\hline & $80-84$ & 38.1 & 37.8 & 37.6 & 37.6 & 37.3 & -0.8 \\
\hline & $85+$ & 30.3 & 28.4 & 28.7 & 28.8 & 28.8 & -1.5 \\
\hline \multirow[t]{2}{*}{ Sex } & Male & 31.1 & 30.7 & 30.4 & 30.1 & 29.3 & -1.8 \\
\hline & Female & 42.6 & 41.7 & 40.8 & 40.2 & 39.2 & -3.4 \\
\hline \multirow[t]{2}{*}{ Type of Insurance } & $\mathrm{NHI}$ & 50.2 & 48.1 & 46.1 & 44.1 & 41.8 & -8.4 \\
\hline & Medical Aid & 12.7 & 12.3 & 12.7 & 13 & 13.5 & 0.8 \\
\hline
\end{tabular}



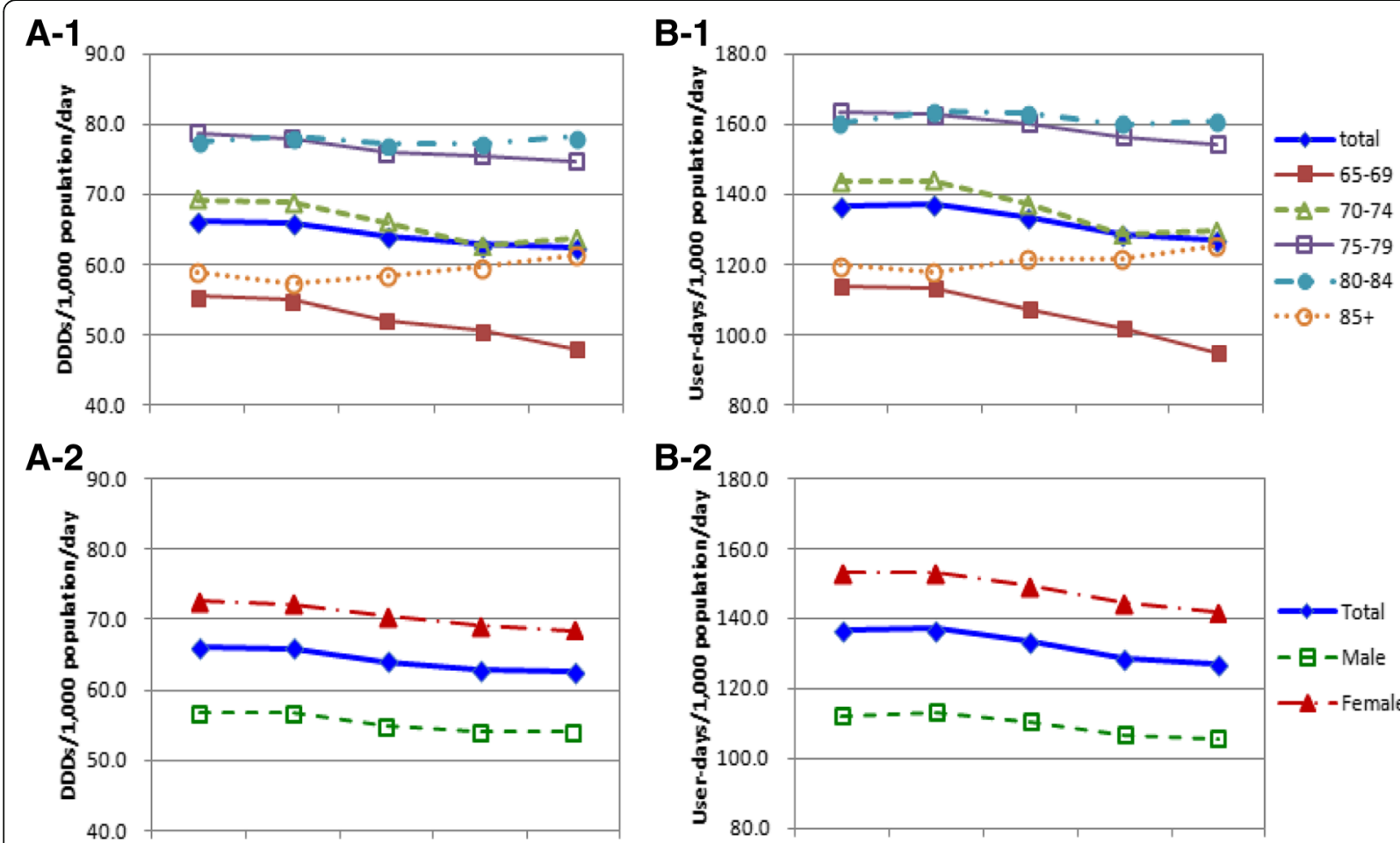

B-2

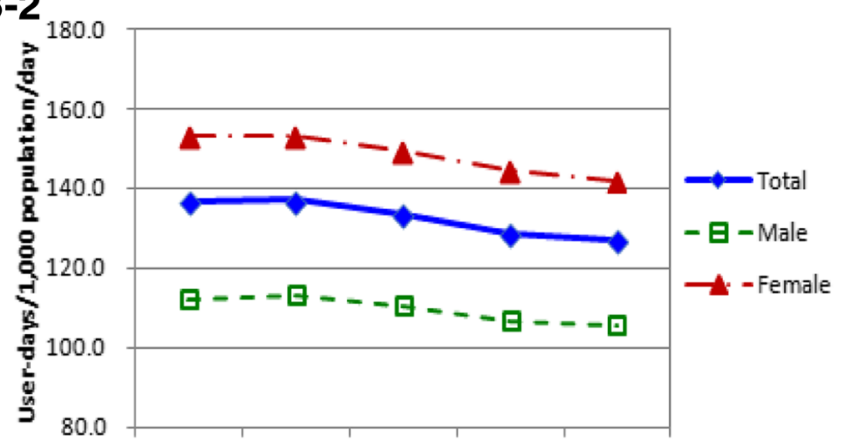

\section{A-3}

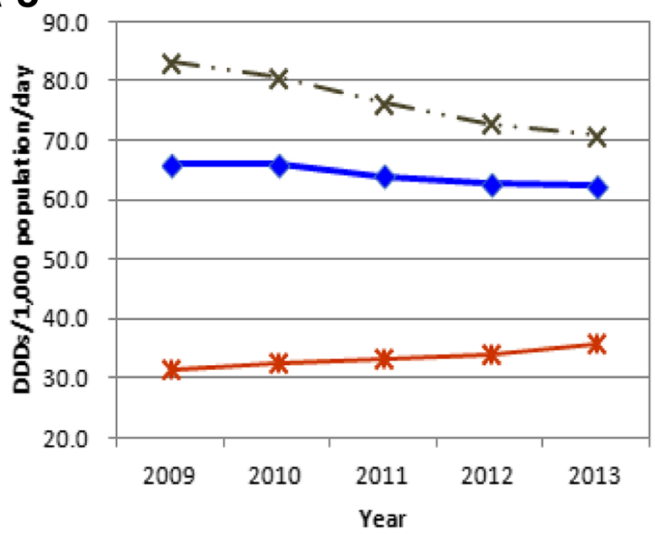

B-3

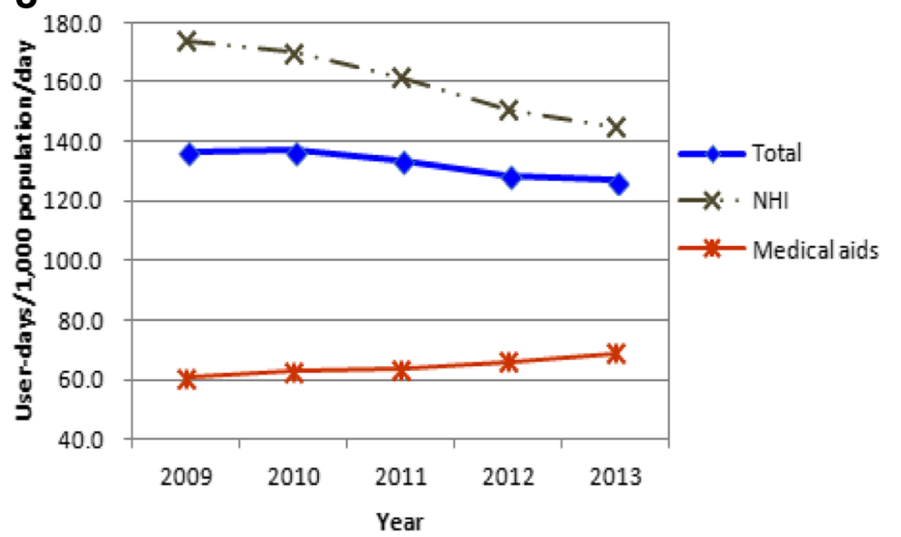

Fig. 1 The patterns of benzodiazepine prescriptions in terms of quantities (A) and durations (B) by age (1), sex (2), and type of insurance (3). $\mathrm{NHI}=$ National Health Insurance

benzodiazepine prescriptions among the older population in our study was higher than in other countries (8.7-31.9\%), although there were some differences in the ages among the studies (over 65 years, $65-80$ years, and over 60 years) [1, 14-16]. Compared with previous reports on the use of benzodiazepines in older people in Korea, the prevalence rate was lower than the $50.3 \%$ observed among elderly outpatients in 2005 and 2006 and the $46.0 \%$ shown in the 5\% sampling data collected for all settings between 2007 and 2011 $[7,17]$. These differences may be mainly due to the inclusion and exclusion criteria, because we excluded the $\sim 10 \%$ of patients who received benzodiazepine prescriptions that were not assigned an ATC-DDD for international comparison. Regardless of the differences between studies, benzodiazepines are still widely prescribed for the elderly in Korea. Moreover, the total volume of benzodiazepines prescribed has recently increased for the older subjects and patients receiving Medical Aid.

Our results suggest that the patterns of benzodiazepine use by the elderly in Korea are concerning, because these drugs are still very commonly prescribed. Although they tend to be low-dose prescriptions, the drugs are prescribed for the long-term, and their use is increasing for more vulnerable patients. 
Table 2 Inappropriate long-term use of benzodiazepines prescriptions from 2009 to 2013

\begin{tabular}{|c|c|c|c|c|c|c|c|c|}
\hline & & & 2009 & 2010 & 2011 & 2012 & 2013 & $\begin{array}{l}\text { Difference } \\
\text { 2009-2013 }\end{array}$ \\
\hline & & & \multicolumn{6}{|c|}{ (numbers per 1000 elderly population) } \\
\hline \multirow[t]{10}{*}{ DDD } & Total & & 12.2 & 12 & 11.4 & 11.6 & 11.6 & -0.6 \\
\hline & Age group (year) & $65-69$ & 10.1 & 9.9 & 9.4 & 9.6 & 9.3 & -0.8 \\
\hline & & $70-74$ & 12.9 & 12.7 & 11.9 & 11.6 & 12 & -0.9 \\
\hline & & $75-79$ & 14.7 & 14.5 & 13.6 & 14 & 13.9 & -0.8 \\
\hline & & $80-84$ & 14.7 & 14.3 & 13.5 & 14.1 & 14.1 & -0.6 \\
\hline & & $85+$ & 10.2 & 9.5 & 9.4 & 9.9 & 10.1 & -0.1 \\
\hline & Sex & Male & 11.3 & 11.2 & 10.5 & 10.6 & 10.8 & -0.5 \\
\hline & & Female & 12.9 & 12.6 & 12 & 12.2 & 12.2 & -0.7 \\
\hline & Type of Insurance & $\mathrm{NHI}$ & 14.9 & 14.5 & 13.3 & 13.1 & 13 & -1.9 \\
\hline & & Medical Aid & 6.8 & 6.5 & 6.7 & 7.1 & 7.2 & 0.4 \\
\hline \multirow[t]{10}{*}{ User-days } & Total & & 42.6 & 43 & 41.3 & 39.2 & 38.5 & -4.1 \\
\hline & Age group (year) & $65-69$ & 34.1 & 34.2 & 31.9 & 29.7 & 27.7 & -6.4 \\
\hline & & $70-74$ & 45.2 & 45.4 & 42.5 & 39.1 & 39.3 & -5.9 \\
\hline & & $75-79$ & 52.5 & 52.9 & 50.9 & 49.3 & 48.5 & -4.0 \\
\hline & & $80-84$ & 51.6 & 53 & 52.3 & 50.2 & 50.3 & -1.3 \\
\hline & & $85+$ & 35.9 & 35.8 & 36.5 & 36.6 & 37.1 & 1.2 \\
\hline & Sex & Male & 35.2 & 36 & 34.8 & 32.8 & 32.6 & -2.6 \\
\hline & & Female & 47.5 & 47.8 & 45.7 & 43.7 & 42.8 & -4.7 \\
\hline & Type of Insurance & $\mathrm{NHI}$ & 53.5 & 53.3 & 49.7 & 45.5 & 44.1 & -9.4 \\
\hline & & Medical Aid & 20.2 & 19.7 & 20.3 & 20.9 & 20.9 & 0.7 \\
\hline
\end{tabular}

NHI National Health Insurance

\section{Inappropriate use of benzodiazepines}

In this study, we considered 365 DDDs/yr. and 365 days/yr. the cut-off point to define inappropriate use. Even with these very generous criteria, more than 11 per 1000 elderly population in terms of the DDDs and more than 38 per 1000 elderly population in terms of user-days were estimated to have been inappropriately prescribed benzodiazepines. This accounted for $3.3 \%$ and $11.0 \%$ of the elderly benzodiazepine users in terms of the DDDs and user-days in 2013, which was much higher than the rate indicated in a recent German report (4.8 per 1000 elderly based on the DDDs) [18]. However, according to the benzodiazepine use in the North Eastern Health Board region of the Republic of Ireland in

Table 3 Inappropriate use of long-acting benzodiazepines from 2009 to 2013

\begin{tabular}{|c|c|c|c|c|c|c|c|}
\hline & & 2009 & 2010 & 2011 & 2012 & 2013 & $\begin{array}{l}\text { Difference } \\
\text { 2009-2013 }\end{array}$ \\
\hline & & \multicolumn{6}{|c|}{ (numbers per 1000 elderly population) } \\
\hline Total & & 263.6 & 252.9 & 242.1 & 233.6 & 220.4 & -43.2 \\
\hline \multirow[t]{5}{*}{ Age group (year) } & $65-69$ & 255.8 & 246.5 & 229.7 & 219.8 & 196.5 & -59.4 \\
\hline & $70-74$ & 281.7 & 272.2 & 259.3 & 246.1 & 240.7 & -41.1 \\
\hline & $75-79$ & 282.8 & 270.8 & 266.8 & 262 & 249.7 & -33.1 \\
\hline & $80-84$ & 254.7 & 246.4 & 240.9 & 236.7 & 227.9 & -26.8 \\
\hline & $85+$ & 187.2 & 169.4 & 165.5 & 161.5 & 155.5 & -31.6 \\
\hline \multirow[t]{2}{*}{ Sex } & Male & 210.2 & 202.8 & 194.8 & 187.3 & 176.6 & -33.6 \\
\hline & Female & 299.9 & 287.3 & 274.9 & 266.1 & 251.6 & -48.3 \\
\hline \multirow[t]{2}{*}{ Type of Insurance } & $\mathrm{NHI}$ & 352.9 & 328.9 & 307.6 & 287 & 264.4 & -88.5 \\
\hline & Medical Aid & 80.7 & 80.3 & 79.1 & 79.5 & 79.7 & -1.0 \\
\hline
\end{tabular}


Table 4 Adjusted odds ratios with 95\% Cls of inappropriate long-term benzodiazepines use, 2013

\begin{tabular}{|c|c|c|c|c|c|c|c|}
\hline \multirow{3}{*}{$\begin{array}{l}\text { Characteristics } \\
\text { Age group (per } 10 \text { years) }\end{array}$} & & \multicolumn{3}{|l|}{ DDDs } & \multicolumn{3}{|c|}{ User-days } \\
\hline & & \multicolumn{2}{|c|}{ Adjusted Odds ratio (95\% Cls) } & \multirow{2}{*}{$\begin{array}{l}p \text { value } \\
<.001\end{array}$} & \multicolumn{2}{|c|}{ Adjusted Odds ratio (95\% Cls) } & \multirow{2}{*}{$\frac{p \text { value }}{<.001}$} \\
\hline & & 0.995 & $(0.994,0.996)$ & & 1.006 & $(1.005,1.007)$ & \\
\hline \multirow[t]{2}{*}{ Sex } & Male & 1.366 & $(1.345,1.389)$ & $<.001$ & 1.137 & $(1.125,1.148)$ & $<.001$ \\
\hline & Female & 1.000 & Ref. & & 1.000 & Ref. & \\
\hline \multirow[t]{2}{*}{ Type of Insurance } & $\mathrm{NHI}$ & 1.000 & Ref. & & 1.000 & Ref. & \\
\hline & Medical Aid & 1.398 & $(1.367,1.431)$ & $<.001$ & 1.178 & $(1.160,1.195)$ & $<.001$ \\
\hline \multirow[t]{5}{*}{ No. of utilization of institutions } & 1 & 1.000 & Ref. & & 1.000 & Ref. & \\
\hline & 2 & 1.555 & $(1.526,1.584)$ & $<.001$ & 1.54 & $(1.523,1.557)$ & $<.001$ \\
\hline & 3 & 1.888 & $(1.843,1.933)$ & $<.001$ & 1.888 & $(1.858,1.918)$ & $<.001$ \\
\hline & 4 & 2.239 & $(2.165,2.315)$ & $<.001$ & 2.265 & $(2.210,2.322)$ & $<.001$ \\
\hline & $5+$ & 2.966 & $(2.850,3.087)$ & $<.001$ & 3.199 & $(3.095,3.306)$ & $<.001$ \\
\hline \multirow[t]{2}{*}{ At least one prescription $w /+30$ days } & No & 1.000 & Ref. & & 1.000 & Ref. & \\
\hline & Yes & 3.368 & $(3.314,3.423)$ & $<.001$ & 8.237 & $(8.156,8.318)$ & $<.001$ \\
\hline \multirow[t]{2}{*}{ At least one prescription for psychiatric disorders } & No & 1.000 & Ref. & & 1.000 & Ref. & \\
\hline & Yes & 7.050 & $(6.925,7.177)$ & $<.001$ & 2.946 & $(2.917,2.976)$ & $<.001$ \\
\hline
\end{tabular}

NHI National Health Insurance, $\mathrm{Cl}$ Confidence Intervals

2002, 9.7\% of benzodiazepine patients in the General Medical Service (which supplies all medicine to the socially-disadvantaged and people $\geqq 70$ years) had prescriptions every month during a year [19]. Because direct comparisons of different studies were hampered by the different definitions of long-term or chronic use (e.g., repeated sporadic use, prescriptions 100-365 days, or 100-365 DDDs and over per year, etc.), the units of measure, and the study populations, we are unable to determine whether these levels were higher or lower than those of other countries [1, 18-25].

However, the use of long-acting benzodiazepines in the elderly population is concerning, because the Beers guideline strongly advises that they not be used by older people except for specific indications such as seizure disorders, benzodiazepine withdrawal, ethanol withdrawal, severe generalized anxiety disorder, and periprocedural anesthesia. Despite the trend toward a slow decrease in inappropriate use, over one-fifth of the elderly population and nearly two-thirds of elderly benzodiazepine users still received at least one prescription for a longacting benzodiazepine. This was almost 7 times higher than the results in the German study (242.1 in Korea vs. 33 per 1000 elderly at 2011) and 2.6 times higher than that of American benzodiazepine users aged 65 to 80 (69.5\% in Korea in 2009 vs. $23.8 \%$ in the United States in 2008) $[1,18]$. This is consistent with a study result that showed that long-acting benzodiazepines accounted for $53.7 \%$ of the prescriptions of benzodiazepines in Korean elderly outpatients [17].

This result indicates that the prescribing of longacting benzodiazepine in this population was at a high level, which is against the advised guidelines, and a considerable number of elderly patients have been exposed to a high risk of sedative effects and psychomotor impairment.

Factors potentially related to inappropriate long-term use All of the factors we considered may contribute to the inappropriate long-term benzodiazepine use in the elderly. In particular, the elderly patients and physicians' behaviors (e.g., the same patient visiting multiple institutions within a year and physicians prescribing at least one benzodiazepine prescription for $\geqq 30$ days) as well as the patients' demographic and clinical characteristics, might have affected the inappropriate long-term use of benzodiazepines.

There is no systematic intervention and monitoring system that functions as a gatekeeper to control medical use across multiple health care institutions, and regulations for limiting prescription days at a single visit have been applied only for some hypnotics/sedatives and triazolam in Korea. [7] In this situation, physicians may have difficulty raising the issue of dependence and applying benzodiazepine withdrawal programs, because patients may transfer to another practitioner who will meet their demands [19].

In addition, the receipt of at least one benzodiazepine prescription for psychiatric disorders (e.g., anxiety, depression, insomnia, and ordinary life stresses) might be another key factor leading to inappropriate use among elderly patients. Benzodiazepines are initially efficacious for these conditions, but there are withdrawal symptoms, especially in elderly patients [26]. There is a lack 
of information available on the long-term effectiveness of benzodiazepines, and there are increasing concerns about the high risk of adverse events, but prescribers and patients do not always accept such information $[20,27]$. Unfortunately, well-established guidance on good benzodiazepine prescribing or managing strategies for patients with persistent benzodiazepine misuse (e.g., an algorithm for a benzodiazepine reduction program, education, patient information leaflets) does not exist in Korea, mainly due to the low priority placed on and the low level of interest in the quality of prescriptions in primary care.

This discordance between prescribing guidelines and the practice environment and the shortage of guidelines and information on the safe use of benzodiazepines have been postulated as potential explanations for the widespread use of benzodiazepines and the lack of improvement in their inappropriate use.

\section{Implications for policy}

The results of the present study indicate that the substantial inappropriate use of benzodiazepines and related drugs may be related to the absence of a "gatekeeper" or family doctor in Korea and the absence of official guidance for benzodiazepine prescribing. Because the earlier efforts of the government to limit the prescribing days for some classes of benzodiazepines led to some improvement of benzodiazepine prescription, it is clear that additional policies on the safe use of benzodiazepines and related drugs may be helpful to tackle this problem [7]. First, concurrent drug utilization review (DUR) services, which enroll all people in the national health insurance program and provide safety information in real-time at the stage of prescribing and dispensing [28], may need to add review rules to identify potentially inappropriate benzodiazepine prescriptions in the elderly. Unlike US pharmacy benefit managers, the Korean DUR services mainly focus on drug-drug interactions, ingredient duplications, drug-age conflicts, and drug use during pregnancy, and they have been limited to certain ingredients [29]. Furthermore, there has been no mechanism to ensure the periodic assessment of the various aspects of prescribing, such as an inappropriate treatment duration or over-utilization. Therefore, providing information on the cumulative quantity of potentially inappropriate medications during or after patient treatment will be necessary.

Second, regulations for restricting prescriptions to a 30day supply at a visit should be considered for all kinds of benzodiazepines. Our analysis shows that the patterns of benzodiazepine use in the Korean elderly were low-dose/ long-term, and receiving at least one prescription lasting $\geqq$ 30 days for benzodiazepines was positively associated with inappropriate use. However, limiting the prescription days for drugs with a high risk of inappropriate use, such as triazolam, has had a little effect on the total quantity of benzodiazepines prescribed [7], so it is necessary to expand the items considered for restricted prescription days for the elderly.

Third, national efforts to make the guidelines more in tune with Korean practice and the widespread dissemination of information on the low effectiveness and serious risks of long-term benzodiazepine use will be needed. Although researchers developed a list of potentially inappropriate drugs for the elderly population of Korea in 2010, it has not been widely accepted $[11,30]$. Patients and physicians' perceptions and behaviors are key factors that determine the use and misuse of benzodiazepines, and thus, more practical guidelines, education, and campaigns should be considered, especially for elderly patients suffering from psychiatric disorders.

Although there might be some concerns about the unexpected results of stricter enforcement of regulations $[7,20]$, the benefits of improving benzodiazepine use and safety in the elderly will outweigh any drawbacks.

\section{Limitations}

This study is not without several limitations. Since no detailed information about the prescribing physician was recorded in the database, it was not possible to identify physician-related factors, such as the prescribers' views on experiences with benzodiazepines. Second, we analyzed benzodiazepine use in the elderly based on filledprescription and dispensing data, which may not necessarily reflect actual use. Thus, our analysis might have led to an overestimation of benzodiazepine use and inappropriate use. However, because of their properties and association with dependence, it is unlikely that these drugs went unused, especially in long-term users, so we assumed that the prescription and dispensing data are a good proxy for actual usage. In addition, prescribing itself as a process indicator carries an important meaning, as it is the first step to accessing benzodiazepines and related drugs. Third, although the OECD guidelines' suggested indicators are only measured for prescribing undertaken in primary care, we also included prescribing by hospitals, which made it difficult to compare our findings to international data. However, our inclusion criteria are more likely to reflect the Korean situation, because the Korean Government allows hospitals to provide a large scale of services to outpatients, and patients can choose any clinic or hospital without a referral slip [31]. Lastly, the inappropriate prescription of benzodiazepines was measured only in terms of a quantitative approach, based on long-term use. In spite of concerns whether this aspect or some other dimensions really capture the inappropriate prescribing of benzodiazepines, the OECD's PQIs have been agreed upon by a 
range of stakeholders to be a valid and useful method to measure or monitor the prescribing quality at the population-level. [9]

\section{Conclusions}

A small decreasing tendency was observed in the prescribing of long-acting benzodiazepines, some of the most commonly prescribed drugs, but with a high potential for inappropriate use, in elderly patients in Korea. Although limited information was available about the prescribing physician, the inappropriate long-term use of benzodiazepines in the elderly was significantly related to the patients and physicians' behaviors, as well as the patients' demographic and clinical characteristics. Introducing prescribing quality indicators (PQIs) in primary health care may be useful for lowering the prescription rate of potentially inappropriate drugs. We suggest that policy efforts, such as periodic assessment of prescribing, restricting prescribing days, and more practical guidelines, are needed to improve the prescribing quality.

\section{Abbreviations}

ATC: Anatomical-Therapeutic-Chemical; DDD: Defined Daily Dose; DUR: Drug utilization review; HCQI: Health Care Quality Indicator; HIRA: Health Insurance Review \& Assessment Service; OECD: Organization for Economic Cooperation and Development; PQI: Prescribing quality indicators

\section{Acknowledgements}

The authors thank Ms. Daseul Kim for her assistance in formatting the manuscript.

\section{Funding}

None.

\section{Availability of data and materials}

Data will be available only if a written request is submitted to and approved by the Health Insurance Review and Assessment Service.

\section{Authors' contributions}

SHH designed the study and drafted the manuscript. SH and HC participated in the design of the study and performed the statistical analyses. CP and SMK conceived of the study, and participated in its design and coordination. THK participated in the design of the study, finalized all the results and helped to draft the manuscript. All authors read and approved the final manuscript.

\section{Ethics approval and consent to participate}

Not applicable.

\section{Consent for publication}

Not applicable.

\section{Competing interests}

The authors declare that they have no competing interests.

\section{Publisher's Note}

Springer Nature remains neutral with regard to jurisdictional claims in published maps and institutional affiliations.

\section{Author details}

'Health Insurance Review and Assessment Service (HIRA), Wonju, Republic of Korea. ${ }^{2}$ Department of Hospital Administration, Graduate School of Public Health, Institute of Health Services Research, Yonsei University, 50-1 Yonsei-ro, Seodaemun-gu, 03711 Seoul, Republic of Korea.
Received: 31 January 2017 Accepted: 14 August 2017

Published online: 22 August 2017

\section{References}

1. Olfson M, King M, Schoenbaum M. Benzodiazepine use in the United States. JAMA psychiatry. 2015;72(2):136-42.

2. Donoghue J, Lader M. Usage of benzodiazepines: a review. Int J Psychiatry Clin Pract. 2010;14(2):78-87.

3. Bartlett G, Abrahamowicz M, Tamblyn R, Grad R, Čapek R. Berger Rd: longitudinal patterns of new benzodiazepine use in the elderly. Pharmacoepidemiol Drug Saf. 2004;13(10):669-82.

4. Madhusoodanan S, Bogunovic OJ. Safety of benzodiazepines in the geriatric population. Expert Opin Drug Saf. 2004;3(5):485-93.

5. Campanelli C: American Geriatrics Society. Beers criteria update expert panel. American Geriatrics Society updated Beers Criteria for potentially inappropriate medication use in older adults J Am Geriatr Soc. 2012; 2012(60):616-31.

6. Landreat MG, Vigneau CV, Hardouin JB, Bronnec MG, Marais M, Venisse JL, Jolliet P. Can we say that seniors are addicted to benzodiazepines? Substance use \& misuse. 2010:45(12):1988-99.

7. Weber MA, Schiffrin EL, White WB, Mann S, Lindholm LH, Kenerson JG, Flack JM, Carter BL, Materson BJ, Ram CVS. Clinical practice guidelines for the management of hypertension in the community. The journal of clinical hypertension. 2014;16(1):14-26.

8. Lader M. Benzodiazepine harm: how can it be reduced? Br J Clin Pharmacol. 2014;77(2):295-301.

9. Directorate for Employment L, and Social Affairs Health Committee: Quality Indicators based on data about prescribing of medication in primary health care; Opportunities for intrnational Comparison. In: Health Care Quality Indicator. OECD; 2012.

10. Health expenditure and financing [http://stats.oecd.org/Index aspx?DataSetCode=SHA]

11. Jang IY, Lee YS, Jeon MK, Cho H, Oh JS, Lee Y, Park H, Kim SH, Lee E. Potentially inappropriate medications in elderly outpatients by the 2012 version of beers criteria: a single tertiary medical center experience in South Korea. Journal of the Korean Geriatrics Society. 2013;17(3):126-33.

12. Jung $\mathrm{H}-\mathrm{K}$, Kim $\mathrm{YH}$, Park JY, Jang BH, Park S-Y, Nam M-H, Choi M-G. Estimating the burden of irritable bowel syndrome: analysis of a nationwide korean database. Journal of neurogastroenterology and motility. 2014;20(2):242-52.

13. Jin X-M, Lee J, Choi N-K, Seong J-M, Shin J-Y, Kim Y-J, Kim M-S, Yang BR, Park B-J. Utilization patterns of disease-modifying antirheumatic drugs in elderly rheumatoid arthritis patients. J Korean Med Sci. 2014;29(2):210-6.

14. Petitjean S, Ladewig D, Meier CR, Amrein R, Wiesbeck GA. Benzodiazepine prescribing to the Swiss adult population: results from a national survey of community pharmacies. Int Clin Psychopharmacol. 2007;22(5):292-8.

15. Windle A, Elliot E, Duszynski K, Moore V. Benzodiazepine prescribing in elderly Australian general practice patients. Aust N Z J Public Health. 2007; 31(4):379-81.

16. Lagnaoui $\mathrm{R}$, Depont F, Fourrier A, Abouelfath A, Begaud B, Verdoux $H_{\text {, }}$ Moore N. Patterns and correlates of benzodiazepine use in the French general population. Eur J Clin Pharmacol. 2004;60(7):523-9.

17. Kim Y, Jung S, Choi N, Kim H, Kim J, Chang Y. Benzodiazepine prescription patterns for the elderly patients at ambulatory care in Korea. J Pharmacoepidemiol Risk Manag. 2008;1:60-7.

18. Gisbert S, Irene L, Ingrid S. Prescribing indicators: an OECD initiative with first results from Germany. German Medical Science. 2013;

19. Henman M, Vivero L, Gustafsson A, Mulvenna K: Benzodiazepine usage in the north eastern health board region of the Republic of Ireland. 2004.

20. Neutel Cl, Skurtveit S, Berg C. What is the point of guidelines? Benzodiazepine and z-hypnotic use by an elderly population. Sleep Med. 2012;13(7):893-7.

21. Neutel Cl, Skurtveit S, Berg C: Benzodiazepine and z-hypnotic use in Norwegian elderly, aged 65-79. Norsk epidemiologi 2012, 22(2).

22. Zandstra S, Van Rijswijk E, Rijnders C, Van De Lisdonk E, Bor J, Van Weel C, Zitman F. Long-term benzodiazepine users in family practice: differences from short-term users in mental health, coping behaviour and psychological characteristics. Fam Pract. 2004;21(3):266-9.

23. Manthey L, van Veen T, Giltay EJ, Stoop JE, Neven AK, Penninx BW, Zitman FG. Correlates of (inappropriate) benzodiazepine use: the Netherlands study of depression and anxiety (NESDA). Br J Clin Pharmacol. 2011;71(2):263-72. 
24. Cunningham CM, Hanley GE, Morgan S. Patterns in the use of benzodiazepines in British Columbia: examining the impact of increasing research and guideline cautions against long-term use. Health Policy. 2010; 97(2):122-9.

25. Sonnenberg CM, Bierman EJ, Deeg DJ, Comijs HC, van Tilburg W, Beekman AT. Ten-year trends in benzodiazepine use in the Dutch population. Soc Psychiatry Psychiatr Epidemiol. 2012;47(2):293-301.

26. Ashton $\mathrm{H}$. The diagnosis and management of benzodiazepine dependence. Current opinion in Psychiatry. 2005;18(3):249-55.

27. Cook JM, Marshall R, Masci C, Coyne JC. Physicians' perspectives on prescribing benzodiazepines for older adults: a qualitative study. J Gen Intern Med. 2007;22(3):303-7.

28. (HIRA) HIRA: Developer Training Program of DUR for Safe Drug Use. In Seoul, Korea: HIRA; 2010.

29. Heo $\mathrm{JH}$, Suh DC, Kim S, Lee E-K. Evaluation of the pilot program on the realtime drug utilization review system in South Korea. Int J Med Inform. 2013; 82(10):987-95.

30. Kim DS, Heo SI, Lee SH. Development of a list of potentially inappropriate drugs for the korean elderly using the delphi method. Healthcare informatics research. 2010;16(4):231-52.

31. Ock M, Kim J-E, Jo M-W, Lee H-J, Kim HJ, Lee JY. Perceptions of primary care in Korea: a comparison of patient and physician focus group discussions. BMC Fam Pract. 2014;15(1):1.

\section{Submit your next manuscript to BioMed Central} and we will help you at every step:

- We accept pre-submission inquiries

- Our selector tool helps you to find the most relevant journal

- We provide round the clock customer support

- Convenient online submission

- Thorough peer review

- Inclusion in PubMed and all major indexing services

- Maximum visibility for your research

Submit your manuscript at www.biomedcentral.com/submit 